\title{
Knowledge Adoption: A New Perspective and the Influence of Knowledge Characteristics
}

\author{
Nan (Tina) Wang \\ Eastern Illinois University \\ nwang@eiu.edu
}

\begin{abstract}
Knowledge may be regarded as one type of innovations that are potentially beneficial to knowledge recipients. However, benefits of knowledge sharing or transfer can only be realized if knowledge recipients are aware of the existence of knowledge, adopt it and deploy it. This paper first provides a review and comparison of innovation characteristics and knowledge characteristics examined in the existing literatures. Then, integrating ideas from the innovation adoption, cognitive psychology and financial real options literatures, this paper provides a new perspective of knowledge adoption that includes two processes (i.e., awareness and evaluation) and three possible adoption decision outcomes (i.e., strong adoption whereby the knowledge is adopted for immediate deployments, weak adoption whereby the knowledge is consciously archived for possible future applications, and faint adoption whereby the knowledge is not adopted for immediate application nor archived for future application). Using the new perspective of knowledge adoption, a set of propositions is offered regarding the influence of knowledge characteristics on adoption decisions. This paper contributes to both knowledge management and innovation adoption literatures.
\end{abstract}

\section{Introduction}

The importance of knowledge sharing and transfer is widely recognized (e.g., [21]; [30]; [33]; [44]; [53]). A recent literature review proposed a six-step process of knowledge transfer, namely, knowledge generation, knowledge adaptation, knowledge dissemination, knowledge reception, knowledge adoption, and knowledge utilization ([8]). While researchers have long recognized the importance of the recipient side ([58]), existing research focused on the provider side (especially the knowledge provider's motivation to share knowledge) and the recipient side received far less attention - one notable exception is the research firm' absorptive capacity (e.g., see [70]). As Dixon argued, existing attention "focus on the person or group who holds the knowledge to be shared. However, the other side of the knowledge equation, the receiver of knowledge, has been largely neglected” ([26], p.36).

This paper focuses on one of the processes of knowledge transfer ([8]), i.e., knowledge adoption. Knowledge adoption is crucial as benefits anticipated from knowledge sharing/transfer cannot be realized until shared knowledge is adopted ([14]) — Just like what Davenport and Prusak [21] argued, “... knowledge that isn't absorbed hasn't really been transferred...” (p.101). All too often, though, shared knowledge fails to be adopted (e.g., [24]; [47]). Despite its importance, knowledge adoption, however, has received limited attention. One exception is Sussman and Siegal [56], which integrated technology acceptance model and dual-process model of information influence to understand antecedents of information usefulness and its impact on knowledge adoption. Another exception is Chou, Wang and Tang [15], which examined how informational determinants (i.e., knowledge quality and source credibility), normative determinants (i.e., knowledge consensus and knowledge rating) and time pressure affect knowledge adoption in virtual communities.

Moreover, this paper focuses on knowledge adoption in the context of informal knowledge sharing or transfer (e.g., coffee room conversation, spontaneous hallway chat [4]). Research has shown that a significant portion of knowledge sharing or transfer occurs informally (e.g., [63]; [66]), yet informal knowledge sharing or transfer has received less attention compared to its formal counterpart (e.g., [23]). This context is also challenging because knowledge recipients may not even realize that potentially valuable knowledge is being shared or exchanged, let alone decide to adopt it.

This paper seeks to provide a deeper understanding of the processes underlying knowledge adoption. To accomplish this objective, this paper borrows insights from the innovation adoption literature-as an individual's decision to adopt knowledge is, in fact, a decision to engage something new for the first time (i.e., innovation) ([56], p.49). Understanding knowledge 
adoption from the perspective of innovation adoption is consistent with the knowledge as personalized information perspective, in which knowledge is "the result of cognitive processing triggered by the inflow of new stimuli” ([4], p. 109). According to this perspective, knowledge management focuses on "exposing individuals to potentially useful information and facilitating assimilation of information” ([4], p. 111).

Applying understandings of the innovation adoption literature to knowledge adoption may be reciprocally beneficial to both fields. On one hand, the innovation adoption literature is valuable for understanding knowledge adoption. Compared to knowledge adoption, innovation adoption has received decades of extensive research attention. Hence, abundant existing insights could be applied to the context of knowledge adoption, or at least could be treated as a starting point for future examination and validation. On the other hand, knowledge adoption may provide insights back to the innovation adoption literature. Knowledge could be viewed as a special type of innovation that is ideational in nature; the adoption of knowledge may also be ideational and does not require resources typical of adopting a technological innovation. This uniqueness of knowledge, as detailed later, may provide new insights (e.g., two-steps of evaluation, different adoption decisions) back to the innovation adoption literature.

Moreover, this paper examines the role of knowledge characteristics on adoption decisions. The importance of understanding knowledge characteristics has been emphasized in the knowledge management literature (e.g., [4]). However, apart from the work on tacitness and stickiness ${ }^{1}$ (e.g., [46]; [57]; [71]), inadequate attention has been directed at understanding the influences of knowledge characteristics-This is a sharp contrast to the extensive studies examining innovation characteristics and their influences on innovation adoption (see [62]; [66] for reviews). This paper's review of the innovation adoption literature and the knowledge management literature, as detailed later, shows that knowledge has similar characteristics as innovation and there are several innovation characteristics that are yet to be applied to knowledge. A set of propositions regarding the influences of knowledge characteristics on adoption decision is developed.

The rest of this paper is organized as follows. A review and comparison of innovation and knowledge characteristics examined in the existing literature is first provided, setting the ground for viewing knowledge as a special type of innovation. After that, a brief review of the innovation adoption literature is offered with an

\footnotetext{
${ }^{1}$ To be exact, stickiness is not a knowledge characteristic, but rather a phenomenon due to the influences of knowledge characteristics
}

emphasis on places that need more attention before being applied to knowledge adoption. Then, integrating ideas from innovation adoption, cognitive psychology and financial real options literatures, this paper proposes a new perspective of knowledge adoption that includes two (i.e., awareness and evaluation) processes and three possible adoption outcomes (i.e., strong adoption, weak adoption, and faint adoption). Finally, a set of propositions is offered regarding the impact of knowledge characteristics on adoption decisions.

\section{Background Literature}

\subsection{Knowledge Characteristics}

Innovation is defined as "an idea, practice, or object that is perceived as new by an individual or other unit of adoption” ([50], p.12). Although most studies in the innovation adoption literature focused on technological innovation (e.g., [32]), researchers have begun to investigate other types of innovation, such as process innovation (e.g., [48]), service innovation (e.g., [29]), strategic innovation ([31]), and management innovation ([10]). Knowledge could be viewed as one type of innovation (e.g., [4]; [50]). The adoption decision making process is essentially about evaluating whether the focal object (be it a technological innovation or knowledge) is better than what individuals already have or other alternatives (e.g., [20]; [54]; [57]; [58]; [66])

A review of the literatures (Table 1) suggests that there is a lot of overlaps between innovation characteristics investigated in the innovation adoption literature and knowledge characteristics investigated in the knowledge management literature: some characteristic (i.e., complexity) is shared by and labeled similarly in both literatures; some characteristics, although labeled differently in the two literatures, are essentially the same. For example, both communicability and tacitness are related to whether it's easy to articulate the focal innovation (i.e., technological innovation or knowledge) to others. Both the innovation adoption and the knowledge management literatures suggest that the more articulable an innovation is, the more likely it is to be adopted (e.g., [11]; [57]); further, there are some characteristics that, although have been examined in only the innovation adoption literature, are likely to be applicable to knowledge adoption. For example, trialability "implies a lesser degree of initial commitment, and therefore individuals ... will more readily adopt an innovation that can be adopted piecemeal” ([40], p. 613). The

(e.g., tacitness), provider/source characteristics (e.g., trustworthiness) and recipient characteristics (e.g., absorptive capacity). 
impact of trialability may still hold for knowledge adoption: if knowledge can be tested on a small scale, then the cost of misusing the knowledge is much lower. Hence, individuals may decide to give the new knowledge a try even if they are not fully convinced by its benefits. The final list of knowledge characteristics considered in this paper is bolded in Table 1.

Table 1. Summary of innovation and knowledge characteristics examined in existing literature Innovation Adoption Literature Knowledge Management Literature

\begin{tabular}{|c|c|c|c|}
\hline \multicolumn{4}{|c|}{ Common characteristic \& similar label } \\
\hline Construct & Citations & Construct & Citations \\
\hline $\begin{array}{l}\text { Complexity: } \\
\text { The extent to which an } \\
\text { innovation is perceived as } \\
\text { relatively difficult to understand } \\
\text { and use. }\end{array}$ & [51]; [62] & $\begin{array}{l}\text { Complexity: } \\
\text { The number of distinct skills } \\
\text { or competencies drew upon } \\
\text { by the knowledge. }\end{array}$ & [36]; [69]; [71] \\
\hline \multicolumn{4}{|c|}{ Common characteristic \& different label } \\
\hline $\begin{array}{l}\text { Communicability: } \\
\text { The extent to which aspects of } \\
\text { the innovation may be conveyed } \\
\text { to others. }\end{array}$ & [11]; [52]; [62] & $\begin{array}{l}\text { Tacitness: } \\
\text { The extent to which the } \\
\text { knowledge is unarticulable, is } \\
\text { rooted in action /experience, } \\
\text { and is situated in context. }\end{array}$ & $\begin{array}{l}\text { [4]; [36]; [46]; [49]; } \\
\text { [57]; [69]; [71] }\end{array}$ \\
\hline $\begin{array}{l}\text { Observability: } \\
\text { The extent to which the results } \\
\text { of an innovation are visible to } \\
\text { others. }\end{array}$ & [1]; [38]; [62]; [64] & $\begin{array}{l}\text { Demonstrability: } \\
\text { The extent to which the } \\
\text { merits of knowledge are } \\
\text { recognizable. }\end{array}$ & [9]; [35]; [69]; [71] \\
\hline $\begin{array}{l}\text { Divisibility: } \\
\text { The possibility for a technology } \\
\text { to stand alone. }\end{array}$ & [69]; [62] & $\begin{array}{l}\text { Independence: } \\
\text { The extent to which the } \\
\text { knowledge is dependent on } \\
\text { others for its application. }\end{array}$ & [9]; [69]; [71] \\
\hline \multicolumn{4}{|c|}{ Unique characteristic } \\
\hline $\begin{array}{l}\text { Trialability: } \\
\text { The extent to which an } \\
\text { innovation may be } \\
\text { experimented on a limited basis. }\end{array}$ & {$[1] ;[38] ;[62]$} & & \\
\hline $\begin{array}{l}\text { Fashionness: } \\
\text { The extent to which an } \\
\text { innovation is currently being } \\
\text { 'hyped' by others. }\end{array}$ & {$[67]$} & & \\
\hline $\begin{array}{l}\text { Compatibility: } \\
\text { The extent to which an } \\
\text { innovation is perceived as being } \\
\text { consistent with the existing } \\
\text { values, past experiences, and } \\
\text { needs of the receivers. }\end{array}$ & {$[51] ;[62]$} & & \\
\hline
\end{tabular}




\subsection{Innovation Adoption}

A review of the innovation adoption literature reveals that considerable emphasis has been placed on adoption decision making (i.e., the evaluation process by [49]) and post-adoption implementation (especially implementation immediately after the decision to adopt) (e.g., [7]; [22]; [38]; [43]; [61]). Within this specific domain, however, two major research gaps are identified.

First, insufficient research attention has been given to understanding how do individuals become aware of an innovation. Prior research has tended to focus on individuals' recognition of an innovation's potential benefits (e.g., [16]; [27]; [39]) but not on recognition of the innovation per se. The recognition of the innovation itself, however, is crucial-Just like what Starbuck and Milliken argued, "If events are noticed, people make sense of them; and if events are not noticed, they are not available for sensemaking." ([55], p.60). Second, the existing literature holds a dichotomous view of adoption decision (adopt or do not adopt). Such dichotomous view of adoption decision is inadequate. For example, it does not explain the phenomenon of individuals archiving the innovation (e.g., downloading a software on one's computer) for possible future use. Keeping the above two research gaps in mind when borrowing insights from the innovation adoption literature, this paper seeks to develop a new perspective of knowledge adoption that also addresses these two gaps.

\section{Theory Development}

Researchers have long recognized that individuals must become aware of a focal object (e.g., a technological innovation, knowledge) before it is evaluated for adoption ([6]; [50]). For example, Rogers argued that "the innovation-decision process begins with the knowledge stage, which commences when an individual (or other decision-making unit) is exposed to an innovation's existence..." ([50], p.171). In the following, this paper proposes a new perspective of knowledge adoption process. Specifically, a brief description of the knowledge awareness process is first offered borrowing insights from cognitive psychology research. After that, incorporating the financial real options perspective (e.g., [41]), this paper argues that, when evaluating knowledge, individuals consider the desirability of both immediate and possible (currently unknown) future deployments; accordingly, there are three possible adoption decisions (i.e., strong adoption, weak adoption and faint adoption). Figure 1 provides an overarching view of the knowledge adoption process.

\subsection{Knowledge Awareness Process}

The awareness process is about initially recognizing the existence of a potentially valuable knowledge for oneself. Knowledge that individuals may become aware of can be provisioned through a variety of sources (e.g., [3]; [17]; [37] [60]) such as a coworker and an individual's memory or note book. Regardless of the source, shared knowledge is first processed by sensory registers (Figure 2). Even though sensory registers have potentially unlimited capacity, some knowledge may still be lost from sensory registers (e.g., coworkers' chats about a potential problem-solving method to someone who is fully focused on a different task). Knowledge sensed by sensory registers enter short-term memory (path 1 in Figure 2), which may decay overtime unless refreshed (i.e., receive continued attention, [18]; [19]) or repeated ([5]). Information in short-term memory may be transferred to long-term memory (path 2 in Figure 2) via repetition or coding, i.e., associating the to-be-remembered information with already-held information ([5]). Information in long-term memory can also be moved to short-term memory (path 3 in Figure 2) if activated by associations (or matching information). For example, when a strawberry lover hears the word 'strawberry', related information held in long-term memory (e.g., a strawberry's smell and taste) may be activated and moved to short-term memory.

The awareness of knowledge relies on a subset of short-term memory that is termed 'focus of attention' (e.g., [42]). Focus of attention holds a limited number (thought to be a range around four to seven) 'chunks' of information used in active cognitive processes ([18]; [42]). For example, it is the focus of attention that holds the assumptions being combined to form a lengthy rhetorical argument. Shared knowledge from providers may enter the focus of attention if the shared knowledge matches with information held in the short-or long-term memory, leading individuals to become aware of the shared knowledge. 


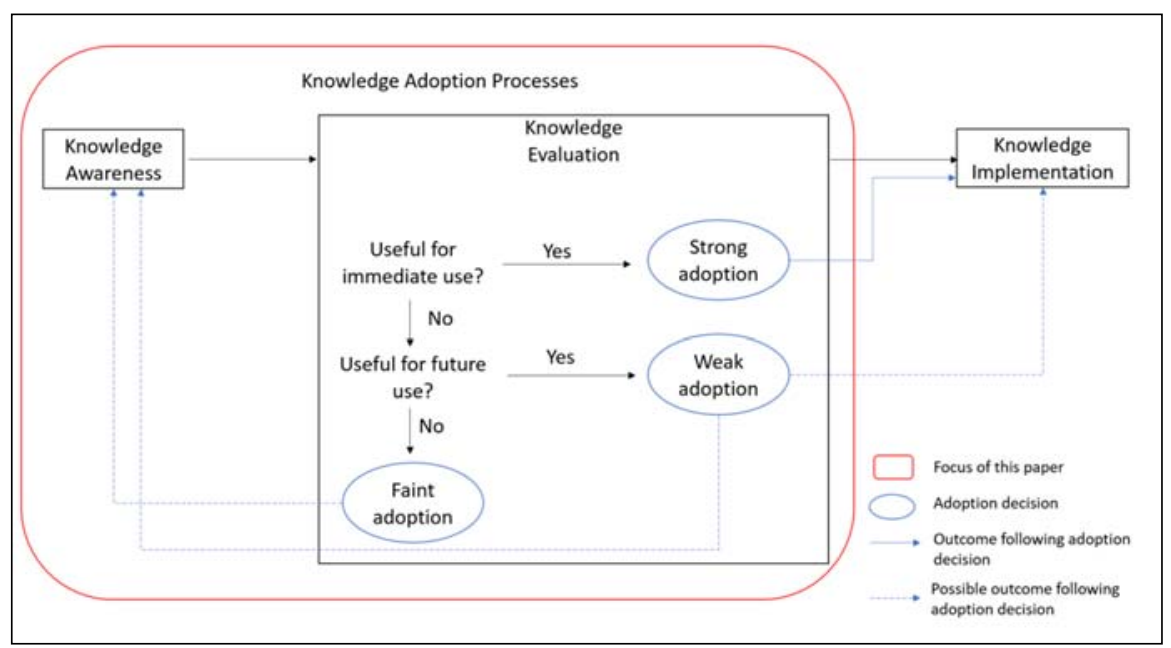

Figure 1. Knowledge adoption process



Figure 2. Knowledge awareness process

\subsection{Knowledge Evaluation Process and Adoption Decision}

There are extensive studies investigating innovation adoption evaluation process leading up to adoption decisions in the extant literature (see [2] for a review). Innovation adoption decision has been treated dichotomously in the existing literature: an innovation is either adopted or not adopted. Knowledge adoption, however, differs from conventional innovation adoption in that the costs of adopting knowledge are generally much lower due to the nature of knowledge being an ideational public good (e.g., [12]; [34]; [71]). In most cases the costs of adopting knowledge are simply some time and cognitive efforts to understand the knowledge. Further, adopted knowledge may be used at any time in the future without concerns about costs typically associated with acquiring but not deploying a technological innovation (e.g., maintenance costs). As a result, compared to technological innovations, individuals are more likely to adopt knowledge without being fully convinced by its benefits or without having a clear plan for (immediately) deploying the knowledge. 
This paper suggests that the knowledge evaluation process leading up to adoption decisions often involves two steps (Figure 1) in which individuals first decide whether or not to adopt the knowledge for immediate application and second, if the immediate application decision is negative, to decide whether or not the knowledge possesses a high probability of future application. If this second decision is affirmative, then the knowledge is consciously archived (ideationally and possibly materially) in some holding areas (e.g., people's memory, physical/electronic storage areas, or a combination of these, e.g., [45]) for future use. The argument for such a two-step formulation finds its basis in research on financial real options ([28]; [41]), which suggests that after making initial investments (e.g., cognitive efforts to understand knowledge), individuals maintain their rights to acquire benefits of the knowledge should following events prove favorable to its application, but can limit losses to only the initial investments should subsequent events prove otherwise.

Corresponding to the two-step evaluation process, there are three possible knowledge adoption decisions: strong adoption where individuals decide to adopt the knowledge for immediate application, weak adoption where individuals decide to adopt (i.e., consciously archive) the knowledge for potential (currently unknown) future application, and faint adoption where individuals decide not to adopt the knowledge for immediate nor future applications yet memory traces of the evaluated knowledge may remain — the label "faint adoption" is preferred over "non-adoption" as individuals are more likely to become aware of knowledge reflected in memory traces (i.e., faintly adopted) than of knowledge that has never been considered for adoption.

The three adoption decisions have different implications. Strong adoption is essentially "the decision to adopt" as examined in the existing innovation adoption literature and is usually followed by knowledge implementation/utilization (solid blue path in Figure 1). With weak adoption where knowledge is consciously achieved in some holding areas, individuals are likely to remember (i.e., become aware of) previously "archived" knowledge when encountering the knowledge (or related issues such as problems that the knowledge solves) again in the future (dashed blue path in Figure 1). In both strong and weak adoptions, knowledge is consciously adopted (for either immediate or future use). Because significantly lower costs and behavioral controls are required in archiving knowledge than in applying knowledge, it is likely that weak adoption occurs more frequently than strong adoption

\footnotetext{
2 This paper does not provide propositions regarding the influence of knowledge characteristics on awareness due to the limited research
}

does. With faint adoption, even though individuals do not consciously archive the knowledge, memory traces of the evaluated knowledge may remain in short-term (or even long-term) memory, which are then likely to facilitate future awareness (dashed blue path in Figure 1). However, because such memory traces are likely to be relatively faint and may decay overtime, the likelihood of the faintly adopted knowledge being activated in the future is less than that for knowledge that were consciously archived (i.e., weak adoption).

\section{Influence of Knowledge Characteristics on Adoption Decision}

Utilizing the above conceptualization of knowledge adoption, this paper develops a set of propositions regarding the influences of knowledge characteristics on adoption decisions ${ }^{2}$. Recall that when making adoption decisions, individuals evaluate the shared knowledge first for immediate application and then for possible future application. If shared knowledge is deemed useful for immediate application, strong adoption occurs; if shared knowledge is deemed useful for possible future application, weak adoption occurs; if shared knowledge is deemed not useful for immediate or future application, faint adoption occurs.

Complexity may have a negative impact on strong/weak adoption and a positive impact on faint adoption. Extensive research on innovation adoption indicated that complexity has a negative impact on individuals' decision to adopt the innovation (e.g., [32]; [66]). In knowledge adoption, such negative impact of complexity is likely to stay no matter whether individuals are evaluating the shared knowledge for immediate application (i.e., strong adoption) or possible future application (i.e., weak adoption) (e.g., [71]). As a result, complex knowledge is more likely to be faintly adopted.

P1: Complexity has a negative impact on strong/weak adoption and a positive impact on faint adoption.

Tacitness may have a negative impact on strong/weak adoption and a positive impact on faint adoption. Innovation adoption research indicates that greater communicability (i.e., lower tacitness) is associated with higher adoption intention (e.g., [62]). In knowledge management, extensive research has shown that tacitness is an obstacle for knowledge transfer (e.g., [13]; [25]). Tacit knowledge resides or is internalized at the provider/source side (e.g., the provider's experience). Hence, it is difficult for knowledge

on awareness in the innovation adoption research. Future research may examine this (important) issue. 
recipients to see values of the tacit knowledge for either immediate or future applications ([36]; [71]).

P2: Tacitness has a negative impact on strong/weak adoption and a positive impact on faint adoption.

For similar reasons as stated above, demonstrability may have a positive impact on strong/weak adoption and a negative impact on faint adoption. Innovation adoption research suggests that greater demonstrability of innovation helps adopters project possible adoption outcomes ([64]) and, as a result, increases the likelihood for individuals to adopt the innovation ([1]; [64]; [72]). When merits of the shared knowledge are easily recognizable, individuals evaluating the knowledge for immediate or possible future applications are more likely to conclude that the shared knowledge is useful. Hence,

P3: Demonstrability has a positive impact on strong/weak adoption and a negative impact on faint adoption.

Independence may have a positive impact on strong/weak adoption and a negative impact on faint adoption. Innovation adoption research has documented the positive impact of divisibility on individuals' decision to adopt (e.g., [62]). Applying the logic to knowledge adoption, it is likely that independence (an equivalent of divisibility) may facilitate the decision to adopt shared knowledge from provider/source. If the application of knowledge depends on others, then individuals, when evaluating the shared knowledge for immediate applications, may be concerned about whether they could actualize the potential benefits of shared knowledge. This issue becomes less of but still a concern when individuals evaluate the knowledge for possible future applications as individuals may or may not be able to acquire required knowledge or skill or capability in the future.

P4: Independence has a positive impact on strong/weak adoption and a negative impact on faint adoption.

P4b: The impact of independence on strong adoption is greater than that on weak adoption.

Trialability may have a positive impact on strong/weak adoption and a negative impact on faint adoption. Research on innovation adoption suggests that when an innovation is characterized by greater trialability, considerable potential exists for individuals to learn about the innovation as a result of directly experiencing the innovation ([1]; [38]; [50]). Though has not received much attention in knowledge adoption, triability is likely to have a positive impact on individuals recognizing values for immediate or future applications. For individuals who are evaluating the knowledge for immediate applications, the opportunity to incrementally deploy the knowledge (via a succession of small-scale implementations) is likely to increase the likelihood that individuals decide to give the knowledge a try; for individuals who are evaluating the knowledge for possible future application, the opportunity to experience the knowledge via a small scale trial during future evaluation process may increase the likelihood that individuals decide to archive the knowledge than to reject the knowledge outright. Hence,

P5: Trialability has a positive impact on strong/weak adoption and a negative impact on faint adoption.

Fashionness may have a positive impact on strong/weak adoption and a negative impact on faint adoption. Fashionable innovations are more likely to be adopted (e.g., [67]) as fashionness enables “...learning about without material engagement...” ([68], p.715). That is, the information-revealing nature of fashionness can provide externally-sourced information or signals to individuals; the greater the fashionness, the greater individuals' confidence that the focal innovation is valuable ([56]). Though has not been examined as a knowledge characteristic, fashionness may impose a similar influence. If the shared knowledge is highly fashionable, individuals are likely to adopt the knowledge for immediate use or to archive the knowledge for possible future use. However, what is fashionable now may not be fashionable in the future. Hence, the positive impact on weak adoption (i.e., archiving for future use) is likely to be weaker than that on strong adoption.

P6: Fashionness has a positive impact on strong/weak adoption and a negative impact on faint adoption.

P6b: The impact of fashionness on strong adoption is greater than that on weak adoption.

Compatibility may have a positive impact on strong/weak adoption and a negative impact on faint adoption. Compatibility has been found to have a positive impact on innovation adoption decisions (e.g., [62]) in that greater compatibility helps individuals recognize the value of the focal innovation. Similarly, if the shared knowledge is compatible with recipient's existing values, past experiences, and etc., knowledge recipients are more likely to find the shared knowledge valuable for either immediate or future applications.

P7: Compatibility has a positive impact on strong/weak adoption and a negative impact on faint adoption.

\section{Discussion}

Knowledge could be viewed as a special type of innovation. Compared to innovation adoption, knowledge adoption as well as the influences of knowledge characteristics have received far less attention in the IS literature. Borrowing ideas from the 
innovation adoption and related (e.g., cognitive psychology) literatures, this paper first proposes a new perspective of knowledge adoption that includes two processes (i.e., awareness and evaluation) and three possible adoption decisions (i.e., strong adoption, weak adoption and faint adoptions). Next, this paper develops a set of propositions regarding the influence of knowledge characteristics on adoption decisions. The ideas presented here embody three contributions to the literature.

First, this paper contributes to the literature on innovation and knowledge adoption by providing a new perspective of knowledge adoption. In this perspective, individuals (i.e., knowledge recipients) need to first become aware of the shared knowledge before evaluating the knowledge for adoption decisions. While activities associated with individuals becoming aware of a new innovation (including knowledge) are critically important (e.g., [6]), the nature of such activities is an understudied phenomenon. Borrowing ideas from the cognitive psychology literature, this paper provides a description of the awareness process prior to the extensively examined evaluation process.

Second, this paper contributes to the innovation adoption literature by providing a new perspective of the evaluation process and adoption decisions. Borrowing ideas from the financial real options literature, this paper argues that individuals go through a two-step process to evaluate the knowledge for first immediate applications and then for possible (currently unknown) future applications. Accordingly, this paper proposes that adoption decision outcomes are not dichotomous in nature (i.e., adopt, do not adopt) but rather involve strong adoption (adopt for immediate applications), weak adoption (archive for possible future applications) and faint adoption (do not adopt for immediate applications or archive for future applications, but memory traces of the evaluated knowledge remain). Also, both weak and faint adoptions may affect future awareness of the shared knowledge, with faint adoption having a relatively weaker impact compared to weak adoption. Thus, even the decision to not adopt for immediate applications can take differentiated and beneficial paths.

Third, this paper provides new insights regarding knowledge characteristics and their influences on adoption decisions. A review and comparison of innovation characteristics and knowledge characteristics is offered, showing that innovation and knowledge are alike. Then, a set of propositions is offered regarding the influence of knowledge characteristics (including some characteristics that have not been examined in the knowledge management literature) on adoption decisions. Future research may use this paper's conceptualization of knowledge adoption (i.e., awareness and evaluation) process to develop further understandings regarding the role of knowledge characteristics on adoption (e.g., the influence of knowledge characteristics on awareness).

Future research may also examine the possible dynamics among the different knowledge adoption decisions. This paper focuses on individuals' initial adoption decisions. As indicated by the innovation adoption literature (e.g., research on innovation and IT/S continuance) (e.g., [7]), individuals may later change their adoption decisions, e.g., after individuals experience the knowledge. Hence, knowledge adoption should be best viewed as an on-going process in which an adoption decision is regularly exercised as knowledge recipients evolve their understandings of the knowledge or the related deployment context. As a consequence, it is possible that the surfacing of new information (about a previously adopted knowledge or about the deployment context) may result in a strong adoption decision transitioning to a weak or faint adoption decision.

\section{Conclusion}

To realize benefits from knowledge sharing or transfer, knowledge recipients need to become aware of the available knowledge, adopt it and implement it. However, all too often, benefits from knowledge sharing or transfer are not realized because knowledge recipients are not aware of the existence of knowledge or fail to grasp its values. By applying and enriching accepted ideas generated from research on innovation adoption and related literatures, this paper produced new insights regarding knowledge as a type of innovation and the knowledge adoption process. In doing so, this paper also contributed fresh thinking regarding the innovation adoption process.

\section{References}

[1] Agarwal, R., and Prasad, J. (1997). The role of innovation characteristics and perceived voluntariness in the acceptance of information technologies. Decision Sciences, 28(3), pp. 557-582.

[2] Al-Natour, S., and Benbasat, I. (2009). The adoption and use of IT artifacts: A new interaction-centric model for the study of user-artifact relationships. Journal of the Association for Information Systems, 10(9), pp.661-685.

[3] Alavi, M. (2000). Managing organizational knowledge. Framing the domains of IT management research: Glimpsing the future through the past: pp. 15-28.

[4] Alavi, M., and Leidner, D. (2001). Review: Knowledge management and knowledge management systems: Conceptual foundations and research issues. MIS Quarterly, 25(1), pp. 107-136. 
[5] Atkinson, R. C., and Shiffrin, R. M. (1968). Human memory: A proposed system and its control processes. Psychology of Learning and Motivation, 2, pp. 89-195.

[6] Bala, H., and Venkatesh, V. (2007). Assimilation of interorganizational business process standards. Information Systems Research, 18(3), pp. 233-365 .

[7] Bhattacherjee, A. (2001). Understanding information systems continuance: An expectation-confirmation model. MIS Quarterly, 25(3), pp. 351-370.

[8] Becheikh, N., Ziam, S., Idrissi, O., Castonguay, Y., \& Landry, R. (2010). How to improve knowledge transfer strategies and practices in education? Answers from a systematic literature review. Research in Higher Education Journal, 7, pp. 1-21.

[9] Birkinshaw, J., Nobel, R., \& Ridderstråle, J. (2002). Knowledge as a contingency variable: do the characteristics of knowledge predict organization structure? Organization Science, 13(3), pp. 274-289.

[10] Birkinshaw, J., Hamel, G., and Mol, M. J. (2008). Management innovation. The Academy of Management Review, 33(4), pp. 825-845.

[11] Brancheau, J. C., andWetherbe, J. C. (1990). The adoption of spreadsheet software: testing innovation diffusion theory in the context of end-user computing. Information Systems Research, 1(2), pp.115-143.

[12] Cabrera, A., and Cabrera, E. F. (2002). Knowledgesharing dilemmas. Organization Studies, 23(5), pp. 687.

[13] Cavusgil, S.T., Calantone, R.J, \& Zhao,Y. (2003). Tacit knowledge transfer and firm innovation capability. Journal of Business \& Industrial Marketing, 18(1), pp. 6-21.

[14] Choi, S. Y., Lee, H., andYoo, Y. (2010). The impact of information technology and transactive memory systems on knowledge sharing, application, and team performance: A field study. MIS Quarterly, 34(4), pp. 855-870.

[15] Chou, C.H., Wang, Y.S., \& Tang, T.I. (2015). Exploring the determinants of knowledge adoption in virtual communities: A social influence perspective. International Journal of Information Management, 35(3), pp. 364-376.

[16] Cohen, W., and Levinthal, D. (1990). Absorptive capacity: a new perspective on learning and innovation. Administrative Science Quarterly, 35(1), pp. 128-152.

[17] Cowan, D. A. (1986). Developing a process model of problem recognition. Academy of Management Review: pp. 763-776.

[18] Cowan, N. (2008). What are the differences between long-term, short-term, and working memory? Progress in Brain Research, 169, pp. 323-338.

[19] Craik, F. I., and Lockhart, R. S. (1972). Levels of processing: A framework for memory research. Journal of Verbal Learning and Verbal Behavior, 11(6), pp. 671-684.

[20] Cummings, J. L., and Teng, B. S. (2003). Transferring R\&D knowledge: the key factors affecting knowledge transfer success. Journal of Engineering and Technology Management, 20(1-2), pp. 39-68.

[21] Davenport, T., and Prusak, L. (1998). Working knowledge: How organizations manage what they know: Harvard Business Press.
[22] Davis, F. (1989). Perceived usefulness, perceived ease of use, and user acceptance of information technology. MIS Quarterly, 13(3), pp. 319-340.

[23] Davison, R. M, Ou, C. X. J. \& Martinsons, M. G. (2013). Information technology to support informal knowledge sharing. Information Systems Journal, 23(1), pp. 89-109.

[24] Dennis, A. (1996). Information exchange and use in group decision making: you can lead a group to information, but you can't make it think. MIS Quarterly, 20(4), pp. 433-457.

[25] Dhanaraj, C. L., Marjorie, A. S., H. K., \& Tihanyi, L. (2004). Managing tacit and explicit knowledge transfer in IJVs: the role of relational embeddedness and the impact on performance. Journal of International Business Studies, 35(5), pp. 428-442.

[26] Dixon, Nancy. (2002). The neglected receiver. Ivey Business Journal, 66(4), pp. 35-40.

[27] Dyer, J. H., andSingh, H. (1998). The relational view: Cooperative strategy and sources of interorganizational competitive advantage. Academy of Management Review, pp. 660-679.

[28] Fichman, R. G. (2004). Real options and IT platform adoption: Implications for theory and practice. Information Systems Research, 15(2), pp. 132-154.

[29] Gallouj, F., and Weinstein, O. (1997). Innovation in services. Research policy, 26(4-5), pp. 537-556.

[30] Grant, R. (1996). Toward a knowledge-based theory of the firm. Strategic Management Journal, 17(10), pp. 109-122.

[31] Hamel, G. (1998). Strategy innovation and the quest for value. MIT Sloan Management Review, 39 (2), pp. 7-14.

[32] Henderson, R. M., and Clark, K. B. (1990). Architectural innovation: The reconfiguration of existing product technologies and the failure of established firms. Administrative Science Quarterly: pp. 9-30.

[33] Huber, G. P. (1991). Organizational learning: The contributing processes and the literatures. Organization Science: pp. 88-115.

[34] Jarvenpaa, S., andStaples, D. (2001). Exploring perceptions of organizational ownership of information and expertise. Journal of Management Information Systems, 18(1), pp. 151-183.

[35] Kane, A. A. (2010). Unlocking knowledge transfer potential: Knowledge demonstrability and superordinate social identity. Organization Science, 21(3), pp. 643660.

[36] Kang, Jina, Rhee, Mooweon, and Kang, Ki H. (2010). Revisiting knowledge transfer: Effects of knowledge characteristics on organizational effort for knowledge transfer. Expert Systems with Applications, 37(12), pp. 8155-8160.

[37] Kankanhalli, A., Tan, B. C. Y., and Wei, K. K. (2005). Contributing knowledge to electronic knowledge repositories: An empirical investigation. MIS Quarterly: pp.113-143.

[38] Karahanna, E., Straub, D. W., and Chervany, N. L. (1999). Information technology adoption across time: a cross-sectional comparison of pre-adoption and postadoption beliefs. MIS Quarterly: pp. 183-213. 
[39] Lane, P. J., and Lubatkin, M. (1998). Relative absorptive capacity and interorganizational learning. Strategic Management Journal, 19(5), pp. 461-477.

[40] Leonard-Barton, D. (1988). Implementation characteristics of organizational innovations. Communication Research, 15(5), pp. 603-631.

[41] McGrath, R. G. (1997). A real options logic for initiating technology positioning investments. Academy of Management Review: pp. 974-996.

[42] Miller, G. A. (1956). The magical number seven, plus or minus two: some limits on our capacity for processing information. Psychological Review, 63(2), pp. 81-97.

[43] Moore, G., and Benbasat, I. (1996). Integrating diffusion of innovations and theory of reasoned action models to predict utilization of IT by end-users, Diffusion and Adoption of Technology: pp. 132-146. London: Chapman \& Hall.

[44] Nahapiet, J., and Ghoshal, S. (1998). Social capital, intellectual capital, and the organizational advantage. Academy of Management Review, 23(2), pp. 242-266.

[45] Nelson, C. A. (1995). The ontogeny of human memory: A cognitive neuroscience perspective. Developmental Psychology, 31(5), pp. 723.

[46] Nonaka, I. (1994). A dynamic theory of organizational knowledge creation. Organization Science, 5(1), pp. 437.

[47] Pfeffer, J., and Sutton, R. I. (2000). The knowing-doing gap: How smart companies turn knowledge into action: Harvard Business Press.

[48] Pisano, G. P. (1996). The development factory: unlocking the potential of process innovation: Harvard Business Press.

[49] Polanyi, M. (1966). The tacit dimension. Prusak, Laurence: Knowledge in Organizations, ButterworthHeinemann, Boston.

[50] Rogers, E. M. (2003). Diffusion of innovation: New York: Free Press.

[51] Rogers, E. M., andShoemaker, F. F. (1971). Communication of innovations: Free Press.

[52] Rothman, J. (1974). Planning and organizing for social change: Action principles from social science research: Columbia University Press.

[53] Spender, J., and Grant, R. (1996a). Knowledge and the firm: overview. Strategic Management Journal, 17(1), pp. 5-9.

[54] Spender, J. C., and Grant, R. M. (1996b). Knowledge and the firm: overview. Strategic management journal, 17, pp. 5-9.

[55] Starbuck, W.H., and Milliken, F.J. 1988. "Executives' Perceptual Filters: What They Notice and How They Make Sense," in The Executive Effect Concepts and Methods for Studying Top Managers, D. Hambrick (ed.). Greenwich. CT: JAI Press, pp. 35-65.

[56] Sussman, S.W., and Siegal, W.S. (2003). Informational influence in organizations: An integrated approach to knowledge adoption. Information Systems Research, 14(1), pp. 47-65.

[57] Szulanski, G. (1996). Exploring internal stickiness: Impediments to the transfer of best practice within the firm. Strategic Management Journal, 17(1), pp. 27-43.
[58] Szulanski, G. (2000). The Process of Knowledge Transfer: A Diachronic Analysis of Stickiness. Organizational Behavior and Human Decision Processes, 82(1), pp. 9-27.

[59] Taylor, S., and Todd, P. (1995). Assessing IT usage: The role of prior experience. MIS Quarterly: pp. 561570.

[60] Thomas, J. B., Clark, S. M., andGioia, D. A. (1993). Strategic sensemaking and organizational performance: Linkages among scanning, interpretation, action, and outcomes. Academy of Management Journal: pp. 239270.

[61] Thompson, R. L., Higgins, C. A., andHowell, J. M. (1991). Personal computing: toward a conceptual model of utilization. MIS Quarterly: pp. 125-143.

[62] Tornatzky, L. G., andKlein, K. J. (1982). Innovation characteristics and innovation adoption-implementation: A meta-analysis of findings. IEEE Transactions on Engineering Management, 29(1), pp. 28-45.

[63] Truran, W.R. (1998). Pathways for knowledge: how companies learn through people, Engineering Management Journal, 10(4), pp. 15-20.

[64] Venkatesh, V., and Davis, F. D. (2000). A theoretical extension of the technology acceptance model: Four longitudinal field studies. Management Science: pp. 186-204.

[65] Venkatesh, V., Morris, M. G., Davis, G. B., andDavis, F. D. (2003). User acceptance of information technology: Toward a unified view. MIS Quarterly: pp. 425-478.

[66] Von Krogh, G. , Ichijo, K. and Nonaka, I. (2000), Enabling Knowledge Creation, Oxford University Press, Oxford and New York, NY

[67] Wang, P. (2010). Chasing the hottest IT: effects of information technology fashion on organizations. MIS Quarterly, 34(1), pp. 63-85.

[68] Wang, P., \& Ramiller, N. C. (2009). Community learning in information technology innovation. MIS Quarterly, 33(4), pp. 709-734.

[69] Winter, S. G. (1987). Knowledge and competence as strategic assets. The Competitive Challenge Strategies for Industrial Innovation and Renewal: pp.159-184.

[70] Zahra, S. A. and G. George (2002). Absorptive capacity: A review, reconceptualization, and extension. Academy of Management Review, 27(2), pp. 185-203.

[71] Zander, U., and Kogut, B. (1995). Knowledge and the speed of the transfer and imitation of organizational capabilities: An empirical test. Organization Science: pp. 76-92.

[72] Zmud, R. W. (1983). The effectiveness of external information channels in facilitating innovation within software development groups. MIS Quarterly, 7(2), pp. 43-58. 